\title{
MISOGINIA COMO RETÓRICA POLÍTICA: O CASO DO MOVIMENTO ANTISSUFRÁGIO
}

\author{
MISOGYNY AS POLITICAL RHETORIC: THE CASE OF THE ANTI-SUFFRAGE MOVEMENT
}

\section{RESUMO}

Este artigo tem o objetivo de analisar os usos políticos da misoginia, tomando como delimitação temática a disputa pelo sufrágio feminino, ocorrida a partir do final do século XIX. Mais especificamente, serão examinadas três táticas empregadas naquele momento, nos Estados Unidos, na França e no Brasil, para incitar ódio em relação às mulheres que lutavam pelo voto: (i) separação entre mulheres boas e mulheres más e categorização das sufragistas na última classe; (ii) definição deste grupo como uma ameaça; (iii) uso de repressão simbólica à identidade coletiva das sufragistas. A utilização deste conjunto de procedimentos comprova que o discurso que ridicularizava as sufragistas, mais do que sexista e desrespeitoso, pode ser caracterizado como misógino, visto que colaborou para uma aniquilação simbólica daquele grupo de mulheres.

Palavras-chave: Misoginia. Política. Feminismo. Antissufrágio.

\begin{abstract}
This work aims to analyze the political uses of misogyny, using as a thematic boundary the dispute for female suffrage, occurred from the end of the 19th century. More specifically, I will examine three tactics used at that time, in the United States, France and Brazil, to incite hatred towards women who were fighting for the vote: (i) the separation women between good ones and bad ones, and the categorization of suffragettes in the last class; (ii) the definition of this group as a threat; (iii) the use of symbolic repression towards the suffragettes' collective identity. The mobilization of this set of procedures proves that the discourse that ridiculed the suffragettes, more than sexist and disrespectful, can be characterized as misogynistic, since it contributed to a symbolic annihilation of that group of women.
\end{abstract}

Keywords: Misogyny. Politics. Feminism. Anti-suffrage.

\section{Considerações iniciais}

"Queimem a bruxa!", gritava uma multidão de homens e mulheres. Alguns empunhavam cruzes, outros, celulares: a cena aconteceu em pleno Brasil do século

Júlia Cavalcanti Versiani dos Anjos

Doutoranda na Universidade Federal do Rio de Janeiro. E-mail: julianjos@gmail.com 
XXI. No dia 7 de novembro de 2017, manifestantes se reuniram em frente a um teatro em São Paulo, no qual falava a filósofa norte-americana Judith Butler ${ }^{1}$. Além de cartazes e gritos de ordem, os autointitulados "cidadãos de bem" levaram uma boneca de tamanho realista com o rosto da pensadora, à qual atearam fogo, numa clara referência à caça às bruxas perpetrada a partir do século XV.

$\mathrm{O}$ fenômeno retomado com tanto entusiasmo pelos protestantes contra a "ideologia de gênero" foi o responsável pela morte violenta de milhares de mulheres acusadas de feitiçaria e pacto com o demônio. A manifestação ocorrida em São Paulo é sintomática para demonstrar como sobrevivem e se atualizam atos de misoginia que funcionam como punição àquelas que não se encaixam nos padrões esperados. Com o tempo, percebeu-se que haveria maneiras bastante menos custosas - e, até mesmo, lucrativas - de controlar o outro sexo.

A misoginia, entretanto, ainda costuma ser enxergada apenas em sua face mais violenta, vista como um preconceito que existe apenas em homens agressivos e brutos. Como procurarei demonstrar, trata-se de uma concepção estreita desta ideia. O ódio às mulheres deve ser analisado, ao invés disso, como propriedade do ambiente social, uma manifestação central da ideologia patriarcal que cumpre uma função política de conformação à ordem (MANNE, 2018).

Para compreender mais sobre o termo, é interessante observar sua origem etimológica. A palavra misoginia remete às partículas do grego "miseó" e "gyné" que, podem ser traduzidas, respectivamente, como "odiar" e "mulher". Na sociedade helênica, porém, a emoção correspondente à "miseó" não era destacada como particularmente abominável ou indigna a um homem virtuoso. Escritores cristãos seguiram tal tradição, acudindo à defesa tanto da ira quanto do ódio. O teólogo Basílio de Cesareia, por exemplo, asseverava que seria necessário ter amor à virtude e ódio ao pecado em igual medida. Tais medidas acompanhavam a visão Aristotélica do ódio como uma emoção moral, gerada a partir da percepção de um vício. Segundo Konstan (2018), o contexto social era o de um Estado em que não havia interesse em conter o preconceito entre etnias e classes - a rivalidade era, em vez disso, explorada e utilizada como combustível para conflitos políticos. $\mathrm{O}$ ódio aparece, então, como parte da sociedade, algo que ajuda, inclusive, a sustentar suas estruturas.

Em sentido semelhante, Peter Gay (1995) coloca no cultivo do ódio o cerne do projeto civilizador da burguesia europeia. O historiador detalha como a aversão cuidadosamente cultivada em relação ao outro - fosse ele um grupo, religião, classe, província ou nação - atendeu a um claro propósito político: a partir da construção de inimigos, promovia-se a concórdia interna e também justificava-se a guerra e a colonização.

Entre os diversos possíveis usos políticos do ódio, concentro-me, na presente análise, na aversão contra mulheres. A discussão será feita a partir de uma associação

1 Mais informações em: MARTINELLI, Andréa. 'Queimem a bruxa': O protesto que pede \#ForaButler e é contra a 'ideologia de gênero'. Huffpost Brasil, 07/11/2017. Disponível em: <https://www.huffpostbrasil. com/2017/11/o7/queimem-a-bruxa-o-protesto-que-pede-forabutler-e-e-contra-a-ideologia-degenero_a_23269386/>. Acessado em: 20/04/2020. 
entre análise histórica e revisão bibliográfica e utilizará como delineamento temporal a disputa pelo sufrágio feminino, ocorrida a partir do final do século XIX. A escolha deste recorte tem o objetivo de contestar duas ideias bastante comuns: primeiro, que o discurso de ódio seria um fenômeno novo, ou que tem se inflamado cada vez mais por culpa da atual "polarização política" e impulsionado pelas ferramentas de redes sociais; segundo, que a misoginia também tem aumentado recentemente como uma reação às conquistas de direitos que as mulheres obtiveram nas últimas décadas, que teriam deixado alguns homens inseguros sobre seu lugar no mundo. Pretendo demonstrar, a contrário senso, que, desde antes que a palavra "feminismo" sequer tivesse sido cunhada, quando mulheres tomavam os primeiros passos para lutar por direitos fundamentais e encontravam escassos aliados, já emergiram discursos que, manifestos por meio das tecnologias disponíveis naquele momento, mobilizavam aversão a este grupo.

Para construir o argumento, lançarei mão de exemplos norte-americanos, franceses e brasileiros. Ainda que cada um destes contextos tenha suas particularidades, pretendo demonstrar como houve semelhanças entre eles no modo como a misoginia foi articulada. Serão analisadas três táticas empregadas para incitar ódio em relação às mulheres que lutavam pelo voto: primeiro, a defesa de uma separação entre mulheres boas e mulheres más e a categorização das sufragistas na última classe; segundo, a definição deste grupo como uma ameaça; terceiro, o uso de soft repression, isto é, repressão sem violência física, mas que deixa marcas indeléveis na identidade coletiva do grupo afetado.

É importante ressaltar que não se trata de categorias estanques - ao contrário, estas táticas agem conjuntamente e se complementam. Vale notar, ainda, que esta lista não é exaustiva: certamente existiram outras maneiras de mobilização de misoginia contra as sufragistas. A análise deste conjunto de procedimentos, porém, já colabora para demonstrar que o discurso empregado para deslegitimar o nascente movimento feminista, mais do que virulento e desrespeitoso, pode ser caracterizado como misógino, visto que colaborou para uma aniquilação simbólica de um grupo de mulheres, representadas como más, depravadas e perigosas. Além de pessoalmente aviltante às envolvidas, estes ideais apresentaram consequências políticas que repercutem nos dias atuais, na medida em que o estigma em torno dos feminismos dificulta, ainda hoje, a identificação de muitas mulheres com os movimentos pelos seus direitos.

\section{Dividir para conquistar: entre os "anjos do lar" e as "sufragistas solteironas"}

Atualmente, o sufrágio feminino é considerado um direito civil básico, do qual até mesmo a mulher mais conservadora se utiliza para defender seus valores. No século XIX, porém, este tema levantou inúmeras controvérsias, contando com 
a oposição tanto de homens quanto de mulheres. Como destaca Frenier (1984), analisando o contexto estadunidense, aqueles que se organizaram contra essa bandeira apresentavam uma retórica contraditória: ora declaravam que o sufrágio feminino seria perigosamente revolucionário, no sentido de que abalaria as estruturas da sociedade e traria sua ruína ao embaralhar os papéis dos homens e das mulheres; ora afirmavam que o voto feminino não faria qualquer diferença, uma vez que as senhoras não se interessavam por - ou não tinham capacidade de compreender política e apenas copiariam a escolha dos maridos.

$\mathrm{O}$ argumento do sufrágio como uma ameaça será analisado com mais profundidade no próximo tópico; no momento, comentarei a ideia de que a maioria das mulheres não se interessariam por política. A princípio, pode parecer uma noção puramente sexista, que desconsidera a existência de mulheres que poderiam, sim, ter afinidade com assunto. O que ocorreu, entretanto, não foi um mero apagamento destas mulheres que se interessavam pelo processo eleitoral, mas sim uma mobilização de ódio em direção a elas.

A ideia de que a maioria das cidadãs femininas simplesmente não desejaria votar abriu espaço para o argumento de que apenas mulheres "da pior espécie" se dignariam a tal ato tão típico da masculinidade. Deste modo, a entrada das mulheres no processo eleitoral degradaria a democracia, uma vez que aumentaria o número do que se considerava "maus votantes" como também tornaria as eleições ainda mais inapropriadas para as senhoras de respeito (HIGGINS, 2004). Diante desta alegação, é possível indagar: quem seriam estas votantes tão nocivas, que degradariam o processo eleitoral?

O trabalho de Palczewski (2005) ajuda a responder esse questionamento e compreender mais sobre a mentalidade daqueles que se colocavam contra o que se tornou a principal pauta do movimento das mulheres naquele período. A autora apresenta cartões postais que foram produzidos em 1909 pela Dunston-Weiler Lithograph Company of New York em oposição ao sufrágio feminino. De acordo com ela, a importância desse tipo de mídia à época é comparável ao poder da Internet para a comunicação entre pessoas atualmente e, portanto, oferece uma vívida crônica dos valores sociais correntes. Esses cartões, por terem custo reduzido e não necessitarem de leitura, circulavam de forma mais abrangente que revistas ou jornais. Além disto, tal como as atuais mensagens no Facebook ou no Whatsapp, amigos, parentes e conhecidos repassavam as mensagens entre si de modo que cada indivíduo não tinha total controle do que iria receber ${ }^{2}$.

A imagem criada por esses postais em relação às supostas novas eleitoras é espantosa, para os padrões da época: fumantes, fraudulentas, sexualizadas, sem

\footnotetext{
2 É importante ressaltar a relevância que os cartões postais detinham à época. Ainda segundo Palczewsi (2005), na Inglaterra e nos Estados Unidos havia colecionadores de postais que se juntavam em clubes e se inscreviam em competições que premiavam as melhores coleções. Era muito comum, também, que pessoas exibissem, em sua sala de estar, álbuns com sua coleção de cartões cuidadosamente organizada - a quantidade e qualidade destes era, inclusive, um demonstrativo da posição social de seu dono. À luz destas informações, é possível compreender o interesse empresarial em produzir este tipo de conteúdo, como foi o caso da Dunston-Weiler Lithograph Company of New York, aqui analisado.
} 
limites ou escrúpulos, como demonstra a figura a seguir (FIG. 1). No primeiro postal, uma mulher compra o voto de outras duas - este seria o modo destas mulheres fazerem campanha: por meio da desonestidade. No segundo postal (FIG. 1), outra sufragette literalmente agarra um homem e beija-o, com tal força que seu chapéu voa, enquanto ele permanece constrangido e atônito - tudo isto, segundo a lógica do postal, com o objetivo de conseguir votos "do jeito mais fácil". Na terceira imagem (FIG. 1), uma mulher tem nas mãos um cigarro e no peito uma faixa intitulada "district leaderess". Ao seu lado, estão diversas placas destacando a candidatura de mulheres que estariam concorrendo à eleição - elas têm, porém, nomes e descrições jocosos, como "Miss Spinster", que pode ser traduzido como "Senhorita Solteirona".

Figura 1: Cartões postais produzidos nos Estados Unidos em 1909 sobre o tema do voto feminino retratando a dita imoralidade das sufragistas.

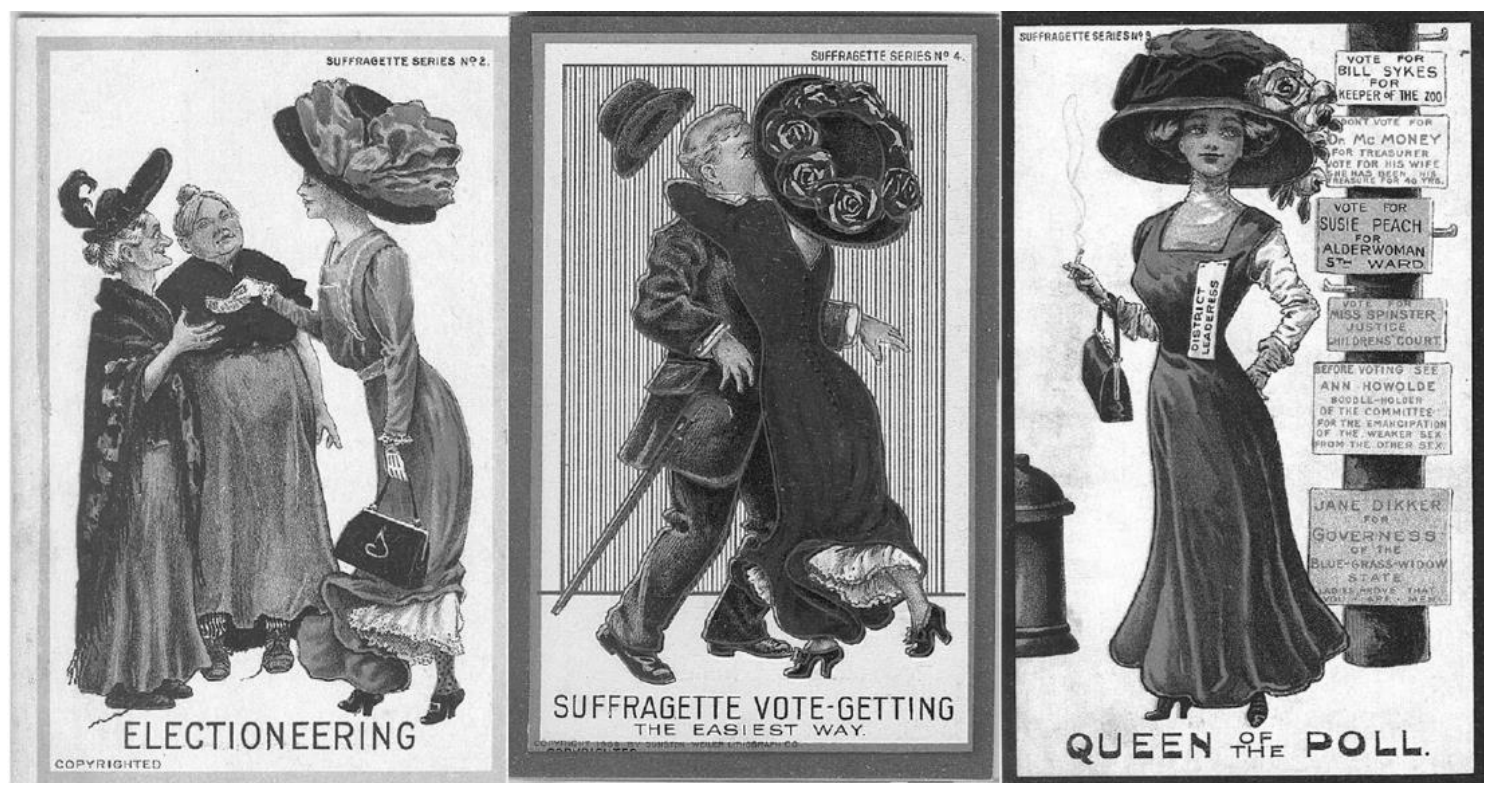

Outro aspecto importante das imagens destacado por Palczewski (2005) é que o fato de as mulheres serem retratadas como femininas, portando vestidos elegantes e chapéus opulentos, não significa que seja uma representação positiva. Em lugar de utilizar a perda da feminilidade como principal argumento, os autores desses postais preferiram apostar na degradação da virtude destas mulheres como mecanismo disciplinar para desestimular outras senhoras a desejar o voto. Assim, as sufragistas são representadas de maneira feminina apenas para serem, também, sexualizadas. Aliás, segundo esta mentalidade, a única possibilidade de uma mulher habitar a esfera pública e conservar sua feminilidade era através da sexualidade exacerbada em outras palavras, uma prostituta ou libertina.

Além das atitudes nas imagens - o fumo, o beijo e o suborno - a sexualização e degradação destas figuras femininas reside em um fato que, para a nossa 
sensibilidade atual, parece completamente corriqueiro, mas, para a visão da época, era escandaloso: expor os calcanhares. De acordo com Palczewski (2005), a norma para a vestimenta das senhoras de respeito no início do século XX era que os vestidos encostassem o chão: no catálogo da loja "Sears" de 1909, mal era possível entrever os sapatos por baixo do volume de saias. Já nas representações das sufragistas nos postais do mesmo ano, os pés estão bem visíveis, sendo que, na primeira e na segunda delas, o calcanhar está exposto, bem como parte da anágua.

O sentimento de que o voto degradaria as mulheres parte tanto do princípio de que aquelas que desejavam o sufrágio eram degeneradas e pervertidas quanto da ideia de que as damas, em sua maioria, eram puras e castas, inclusive moralmente superiores aos homens - autoridade que supostamente perderiam caso fossem às urnas. Em 1912, em panfleto contra o sufrágio feminino, um cardeal expressava a seguinte preocupação: "Se a mulher entrar na política, ela pode ter a certeza de levar consigo um pouco da lama e da sujeira do contato político"3 (PALCZEWSKI, 2005: 375). Negar o voto às mulheres, portanto, não era visto como o indeferimento de um direito fundamental, mas sim como um sensato e urgente ato de proteção contra algo que iria prejudicá-las, na medida em que as retiraria de seu pedestal e extirparia o controle que se considerava que elas detinham sob os homens através de seu charme e de sua feminilidade.

De acordo com esse ponto de vista, o fato de não possuir direito ao voto não significava que a mulher fosse excluída do processo democrático: pelo contrário, a ela era atribuído um projeto muito mais significativo do que meramente inserir um papel em uma urna. À mulher cabia a relevante atividade de cuidado com o lar e a criação dos filhos, ou seja: ela seria a responsável por manter toda a estrutura social funcionando (HIGGINS, 2004). Tal linha de argumentação partia, portanto, da valorização da importância da mulher como forma de justificar a privação de direitos - que, deste modo, não era vista como uma restrição, mas sim como um pequeno sacrifício que vinha com grandes recompensas e funcionava também como uma fonte de prestígio. Assim sendo, é importante lembrar que muitos dos argumentos contra o voto feminino não negavam ostensivamente qualquer forma de poder à mulher, apenas lhe prometiam formas diferentes de consegui-lo - e, por isso, pareciam atrativos para muitas delas. É primordial ressaltar, contudo, que a dama que habitava este pedestal de dignidade era certamente racializada: a figura angelical, casta, doce e totalmente dedicada à maternidade era relacionada à mulher branca, enquanto mulheres negras estiveram associadas à falta de feminilidade, hipersexualização e estereótipos negativos como a "mulher negra raivosa" (KING, 1973).

Além do argumento acerca da importância da mulher para o equilíbrio social, outro modo de convencimento sobre os perigos do direito ao voto era a partir de ameaças veladas ao que poderia acontecer a ela caso se rebelasse contra o marido. Assim, insistia-se no em questionar se a mudança realmente faria bem às mulheres - ou seria apenas um capricho inconsequente e perigoso. Em 1912, um cavalheiro

3 No original: "If woman enters politics, she will be sure to carry away on her some of the mud and dirt of political contact” (PALCZEWSKI, 2005: 375). 
lembrava, em artigo de jornal: "não é, de modo algum, garantido que a instituição do matrimônio que, afinal, é o grande instrumento de nivelamento da situação financeira das mulheres, poderá perdurar sem a subordinação voluntária por parte da esposa"* (FRENIER, 1984: 458). Em outras palavras: caso as mulheres não se submetessem, para além da perda do marido, poderiam ter certeza de que sua situação financeira ficaria arruinada. O casamento é apresentado como um grande aliado da mulher, que a propicia segurança e "nivelamento financeiro" - e, ainda assim, estaria recebendo duros golpes por parte de mulheres inconsequentes.

É possível perceber, portanto, que o movimento antissufrágio estadunidense utilizou amplamente a retórica de separação entre "mulheres honradas" e "mulheres condenáveis", em que as primeiras eram elevadas como moralmente superiores e importantes para a sociedade, enquanto as segundas eram apontadas como desonestas e depravadas. Caso, ainda assim, fosse tentador a uma "mulher de bem" a mudança de lado, a argumentação antissufragista deixava bem claro quais seriam as consequências para ela: além da reprovação e do isolamento social, elas ficariam na penúria, abandonadas por seus maridos.

Este estratagema empregado pelos manifestantes contra o voto feminino nos Estados Unidos demonstra que a ação política que se utiliza da misoginia pode apresentar uma especificidade em relação a outros tipos de discurso de ódio: para obter êxito, não precisa atingir mulheres como um todo. Existem discursos e indivíduos que propagam aversão e desprezo à todas as mulheres, porém esta não é a única e nem a mais comum forma de manifestação da misoginia. Na verdade, este tipo de ódio costuma agir não somente por meio de uma generalização e homogeneização do grupo que atinge, mas principalmente por meio de uma divisão deste: separam-se as mulheres "más", que serão caçadas e punidas, das mulheres "boas", que servirão de padrão de comportamento e auxiliarão na punição das demais (RICHARDSONSELF, 2018; MANNE, 2018).

Apesar desta separação, é importante ressaltar que, ao final, todas as mulheres acabam sendo afetadas por este tipo de ódio, ainda que não de maneira óbvia ou imediata. Mesmo uma mulher que se esforça para ser considerada "boa" corre permanente risco de ser percebida como "má", uma vez que não é ela quem decide à qual categoria pertencer. Muitas vezes, adverte Manne (2018), mulheres podem ser vistas como intercambiáveis, representantes de um certo "tipo" de mulher considerado maligno. As terríveis consequências advindas do fato de pertencer à classe de "mulheres más", portanto, constantemente assombram à todas as mulheres.

Ao mesmo tempo, a figura difusa da "mulher honrada" - cujas qualidades variam dependendo da situação e do homem em questão - funciona como um símbolo manipulado para justificar as agressões contra aquelas que não atingem os mesmos padrões. O imaginário da mulher ideal, deste modo, coexiste em perfeita harmonia com a ideia da mulher como um ser maligno. Figuras femininas como a

4 No original: "It is not at all certain that the institution of matrimony which after all, is the great instrument in the levelling up of the financial situation of women can endure apart from some willing subordination on the part of the wife" (FRENIER, 1984: 458). 
“donzela recatada" e a "mãe protetora" comumente são elogiadas e exaltadas como sendo até mesmo superiores ao homem - o que não anula, contudo, a existência da misoginia. Nutrir sonhos sobre a pureza feminina é um hábito que atua, na verdade, no fortalecimento do ódio às mulheres, uma vez que nega a elas a simples humanidade, encurralando-as entre a santidade ou a demonização.

Assim, "misóginos podem amar suas mães - sem mencionar suas irmãs, filhas, esposas, namoradas e secretárias" (MANNE, 2018: 52). Afinal, para a manutenção do sistema patriarcal, o papel das mulheres é essencial - elas têm uma gama de funções a cumprir. Como homens sexistas não desejam viver sem usufruir das tarefas domésticas, sociais, emocionais, sexuais e reprodutivas associadas às mulheres, a completa eliminação do sexo oposto não seria producente para eles. A misoginia age, portanto, separando as mulheres úteis ao patriarcado daquelas que começam a criar problemas, punindo, preferencialmente, as últimas.

Também é assim que mulheres passam a defender posições misóginas. Aquelas que acreditam pertencer à categoria de "boas mulheres" enxergam a si mesmas como moralmente superiores às demais e agem ativamente no sentido de conservar este status, transferindo esta ideologia a homens e mulheres a sua volta e eventualmente punindo aquelas que não se encaixam em seus elevados padrões. Como lembra Audre Lorde:

(...) é mais fácil para mulheres brancas acreditar na perigosa fantasia de que se você for boa o suficiente, bonita o suficiente, doce o suficiente, ensinar as crianças a comportar-se, odiar as pessoas certas e casar com os homens certos, então a você será permitido coexistir com o patriarcado em relativa paz (LORDE, 1984:119, tradução livre).

A frase de Lorde destaca o fato de que, muitas vezes, o ódio ao outro funciona quase como um pré-requisito para que mulheres sejam consideradas "boas" em meio aos valores patriarcais: tão importante quanto ser bela e doce é sentir aversão àqueles considerados degenerados. Ainda que esta seja uma posição vulnerável - como diz Lorde, uma perigosa fantasia - que pode mudar a qualquer momento ao bel prazer do homem que avalia a honradez da mulher em questão, também é uma posição de privilégio, que não é acessível à todas as mulheres e é utilizada para marginalizar muitas delas, especialmente negras e periféricas.

Esta noção pode ajudar a explicar o comentário de uma mulher em artigo no The New York Times em 1913: "Se as mulheres mantiverem os olhos em suas casas e naqueles dentro delas, as urnas vão cuidar de si mesmas; se elas mantiverem os olhos nas urnas, as casas não vão cuidar de si mesmas. (...) Sufragistas são a favor da destruição dos lares" (FRENIER, 1984: 458). Como se pode perceber, a autora do comentário defende que a atividade de cuidar do lar lhe parecia mais importante do que se envolver em política, mas ela não se contenta em meramente manifestar sua opinião: a afirmação de sua própria importância para a sociedade se dá juntamente 
à diminuição de outras mulheres, às quais ela se opõe. Assim, mulheres que pensam de modo diferente passam de meras dissidentes a um grande perigo. Nesta frase, portanto, é possível perceber, além da separação entre mulheres, outra característica do trabalho discursivo do ódio, que será discutida em detalhes no próximo tópico: a criação do objeto odiado como uma ameaça ao sujeito que odeia.

\section{"Sufragistas são a favor da destruição dos lares": o outro odiado como ameaça}

A ideia de que o sufrágio feminino provocaria a ruína da instituição familiar se tornou amplamente difundida entre o final do século XIX e o início do século XX. É interessante notar que o ato de pensar sobre como seria exatamente este processo de devastação não ficou dependente da imaginação de cada um: os ativistas da causa fizeram uso das tecnologias disponíveis no momento para marcar esse cenário distópico no imaginário social com o máximo de clareza possível. Como resultado, imagens de homens se esmerando em tarefas domésticas enquanto bebês choravam circularam por diversos veículos midiáticos (FIG. 2; FIG. 3).

Figura 2: Cartões postais produzidos nos Estados Unidos em 1909 sobre o tema do sufrágio feminino alertando para o suposto colapso familiar que se seguiria.

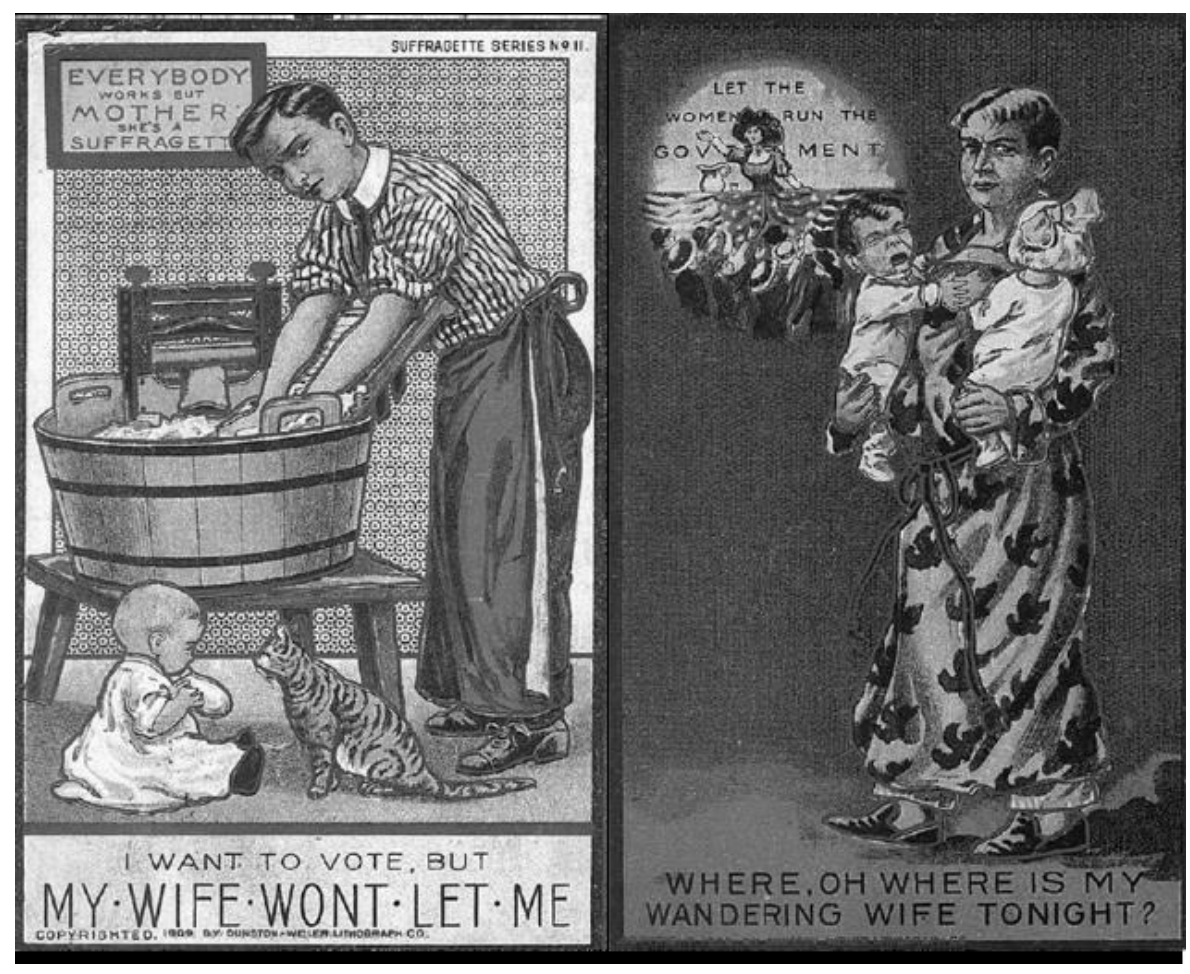

Fonte: Palczewski (2005). 
As duas imagens acima (FIG. 2) fazem parte da já mencionada coleção de cartões postais de 1909 (PALCZEWSKI, 2005). Em uma delas, vemos um homem contrariado, inclinado sobre um tanque de lavar roupas, que diz: "Quero votar mas minha esposa não me permite”. Na imagem, há também uma placa onde se lê: “Todos trabalham, com exceção da mamãe. Ela é uma sufragista”. No postal seguinte, um homem, também de feições irritadas, veste um roupão estampado e carrega bebês no colo, que choram copiosamente. Ele se pergunta "Onde estará minha esposa errante esta noite?”. O desenhista inseriu na imagem a resposta: ela está discursando para uma multidão sobre o direito ao voto.

A ideia da ruína familiar também esteve presente na França. Sobre o contexto francês, Rendall (1985) afirma que a causa sufragista desta região se destaca entre a inglesa e a norte-americana, justamente pela força da resistência antissufragista enfrentada. A autora ressalta que a revolução ocorrida em fevereiro de 1848 naquele país abriu caminho para uma breve explosão de atividade feminista, mas acabou representando uma derrota substancial para este movimento, uma vez que a Assembleia Nacional eleita em abril teve maioria conservadora e as sufragistas também encontraram pouco apoio nos potenciais aliados da esquerda. Após mais uma insurreição, sucedida em junho, o governo decretou que mulheres não poderiam participar de clubes políticos. Com a eleição de Luís Bonaparte, no fim daquele ano, a política se moveu cada vez mais à direita. $\mathrm{O}$ escopo para a atividade política reduziuse sobremaneira na sequência do Golpe de 1851, que inaugurou o Segundo Império Francês. Muitas feministas - inclusive Jeanne Deroin, mencionada nas charges a seguir - não tiveram outra alternativa que não o exílio. Ainda de acordo com Rendall (1985: 298, tradução livre), "o futuro do feminismo francês seria o de um movimento moderado e burguês, relacionado à causa republicana”. E a tradição republicada francesa, ressalta a autora, diferentemente daquela presente nos Estados Unidos, "manteve uma hostilidade inflexível à participação das mulheres na vida pública da república”.

Ainda no ano de 1849, o deboche às sufragistas estava presente na imprensa francesa, como demonstram os dois exemplos abaixo (FIG. 3). A primeira imagem, obra do ilustrador Honoré Daumier, fazia parte de uma série intitulada "Mulheres socialistas"7. Na época, a ativista Jeanne Deroin tentava concorrer a uma posição na Câmara Legislativa e, por isso, era alvo de intenso escárnio e difamação. Na charge, uma mulher agressivamente coloca seu marido para fora de casa, segurando-o pelo pescoço enquanto o filho do casal, desesperado, agarra-se às pernas do pai. "Eu tenho o direito de expulsá-lo da sua própria casa! Jeanne Deroin me provou isto ontem à noite", diz ela. A segunda imagem foi publicada no jornal "L'Illustration" e apresenta

5 No original: "The ultimate future of French feminism was to be that of a moderate and bourgeois movement, connected with the republican cause".

6 No original: "Certainly the republican tradition of 1789, in France, unlike that of the United States, retained an unyielding hostility to women's participation in the public life of the republic".

7 O uso da palavra "feminista" ainda não havia se tornado comum. Segundo Offen (1988), o termo em francês féministe aparece na língua escrita pela primeira vez em 1872. 
uma mulher com saias curtas, fumante e corpulenta no centro da imagem, enquanto um homem está ao fundo, usando avental e cozinhando, com expressão irritada. A legenda deixa claro que a mulher está indo exercer um papel político enquanto ele ficará em casa realizando tarefas domésticas.

Figura 3: Ilustrações publicadas na imprensa francesa em 1849 sobre o que se acreditava serem as consequências, para a família, da participação política feminina.

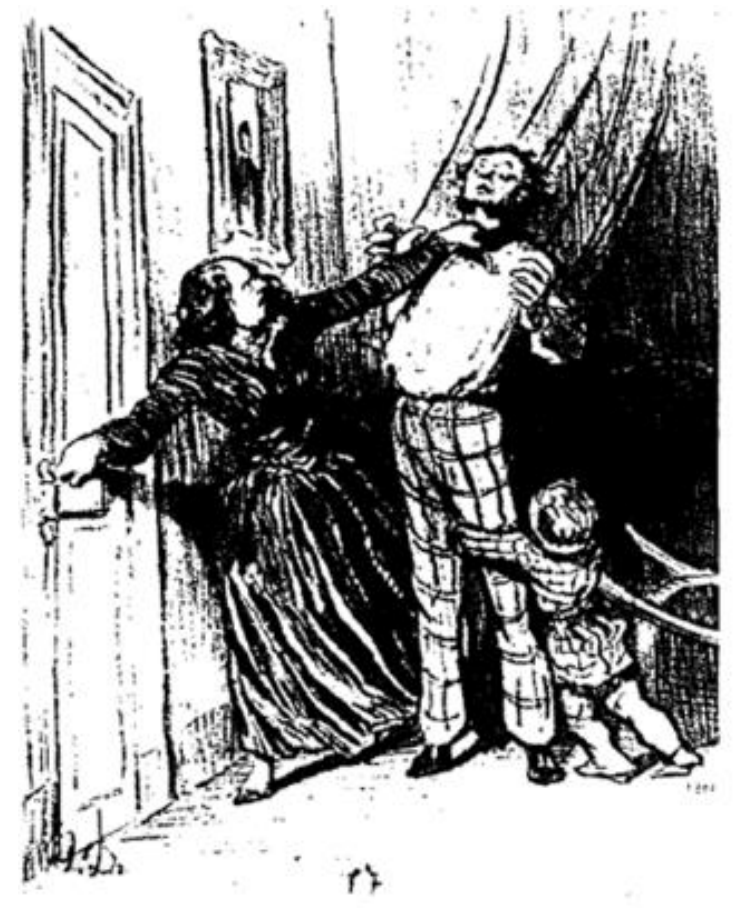

Figure 6. Les Femmes socialistes, 23 May 1849. - So you're my husband, so you're the master. Well, I have the right to throw you out of your homel Jeanne Derouin proved it to me last night. You can go and discuss it with her.

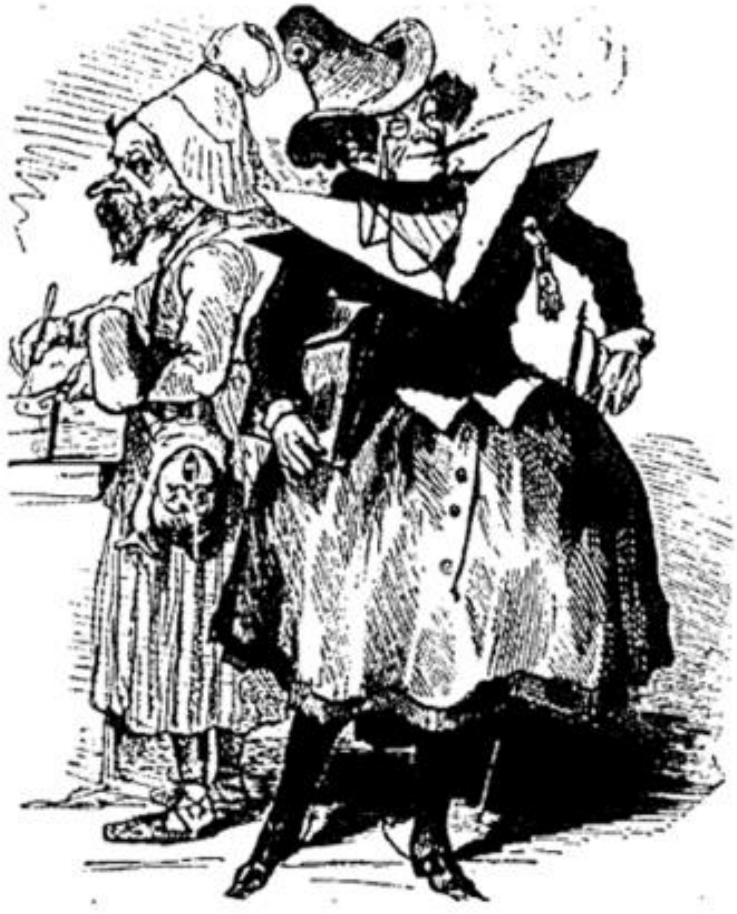

Figure 9. L'Illustration, 24 April 1849.

Citizen on her way to represent her husband in the House (of Representatives) while he represents her in the kitchen.

Fonte: Schor (1996)

Nas quatro figuras acima mencionadas, os homens aparecem tristes e acuados, enquanto as mulheres são representadas comoagressivas ou simplesmente insensíveis. Além do medo de uma inversão de papéis, as imagens demonstram exatamente quais seriam as consequências dessa contraversão: brigas, violência, lares em estado caótico e crianças chorando. Tudo isto, evidentemente, por culpa das mulheres. Não é de se causar espanto, portanto, que, em 1871, um periódico relacionava a luta pelo sufrágio a uma "segunda tentação" de uma "nova Eva" (HIGGINS, 2004: 194).

A imagem da "Primeira Mulher" cedendo ao pecado e caindo em perdição é particularmente interessante uma vez que o sufrágio feminino, de fato, passou a ser relacionado, em diversas produções discursivas, aos comportamentos mais 
libertinos que se pudesse imaginar à época. O voto seria apenas a porta de entrada para uma vida absolutamente desregrada, pervertida e sem limites. Como demonstra Higgins (2004), essa ligação entre sufrágio, promiscuidade e imoralidade foi possível a partir da associação, no imaginário social, entre o nascente feminismo com uma corrente do socialismo influenciada pelos escritos de Henri de Saint-Simon e Charles Fourier. Essa linha de pensamento se tornou conhecida como "socialismo utópico" e alguns de seus seguidores defendiam a livre expressão das paixões, a socialização do trabalho doméstico e até mesmo da sexualidade, abominando a ideia de uma família privada e burguesa enquanto abraçavam os conceitos de amor livre e uniões nãomonogâmicas (FREEDMAN, 2002).

A despeito do fato de que os pensamentos sobre estas questões estavam longe de ser unanimidade até mesmo entre os chamados socialistas utópicos, elas foram consideradas pelos detratores do movimento como a "verdade" subjacente escondida por trás das demandas por igualdade tanto do socialismo quanto do incipiente feminismo (HIGGINS, 2004). Assim, surge um persistente elo que se constituiu na mente popular entre socialismo e imoralidade sexual - associação que passa, também, a assombrar o movimento das mulheres. De acordo com esta linha de pensamento, a disputa pelo voto seria apenas um disfarce para o verdadeiro objetivo do movimento das mulheres: destruir a família e abolir o casamento cristão. Este era o combustível de que o antifeminismo necessitava para tornar o movimento oponente absolutamente abominável para qualquer mulher que se considerasse digna de respeito - argumentação que se encontra presente até os dias atuais.

A sensação de estar desvendando o verdadeiro e profundo caráter ameaçador de uma pessoa ou objeto é típica da emoção de ódio. Como destaca Sarah Ahmed (2014), o ódio costuma funcionar por meio da criação de narrativas sobre o ser odiado, as quais passam a ser vistas como inerentes a ele, quando, na verdade, fazem parte do trabalho desta emoção. Ainda de acordo com Ahmed (2014), estas narrativas costumam operar a partir de cinco eixos: primeiramente, cria-se um sujeito que está em perigo; gera-se, também, um outro ameaçador; em seguida, é preciso que esteja presente a sensação de que este outro está perigosamente próximo e a ideia de que a mera presença deste outro é uma ameaça ao objeto de amor do sujeito; por fim, difunde-se a noção de que o ser odiado não apenas irá danificar o objeto amado, mas também quer tomar o lugar do sujeito. Como se pode perceber, o discurso contra o sufrágio presente nos conteúdos aqui analisados cumpria todas estas cinco etapas.

É interessante notar todas as simplificações e saltos argumentativos que foram feitos para que esta narrativa se concretizasse: os maridos foram representados como seres indefesos, que jamais reagiam à rebeldia de suas esposas; mulheres que, até recentemente, exerciam todas as funções domésticas (do contrário, os maridos já estariam acostumados a estar nesta posição) passaram a ser consideradas relapsas simplesmente por participarem de reuniões políticas; a mera presença destas mulheres nestes locais já seria o suficiente para ameaçar sua família; e, finalmente, considerou-se que elas desejam tomar o lugar dos homens. 
Posicionar o outro como uma ameaça a um ente precioso e indefeso é uma tática política extremamente eficaz pois, além de fornecer uma sensação de importância e urgência ao discurso, ainda permite que o ódio mobilizado seja ressignificado como sentimento de justiça, amor e proteção a valores importantes. O trabalho discursivo do ódio, portanto, constrói um sujeito em perigo e um objeto ameaçador e faz com que estas narrativas pareçam corresponder às realidades profundas sobre aquelas entidades, inegáveis e imutáveis, apagando todo o trabalho feito pela emoção.

Mesmo diante de tamanha oposição, o sufrágio feminino foi conquistado ao longo do século XX e, atualmente, o antifeminismo não questiona que se trata de um direito fundamental da mulher. Esta vitória não significou, entretanto, que a aversão mobilizada em direção às militantes do nascente feminismo tenha sido ineficaz ou que tenha desaparecido. Ainda que as sufragistas tenham conseguido uma vitória, elas sofreram um processo de estigmatização que marcou sua relação da opinião pública. Demonstrarei, no próximo tópico, como a mobilização feminista passou por um processo de repressão que, espalhado ao longo do tempo e sem chamar a atenção, foi extremamente eficiente para a aniquilação simbólica do movimento, o que colabora para que, ainda hoje, a identificação das mulheres com o grupo que pretende representá-las seja um grande desafio.

\section{Entre 1848 e 2018: aniquilação simbólica das vozes femininas}

Em 19 de março de 1848, foi lançado na França o Voix des femmes, um jornal diário que defendia os direitos políticos das mulheres. Dias depois, em 26 de março de 1848 , a publicação humorística Le Charivari trazia um artigo brincando com o nome do periódico feminista: o autor afirmava que sempre foi um admirador das vozes femininas, como a de Marietta Alboni (cantora de ópera famosa à época). Em seguida, ironizava: "Eu temo que os botões possam ser mal costurados nas calças a partir de agora (...). Botões são coisa do passado! Abaixo os botões! Tal será em breve o grito vindo das vozes de todas as mulheres"8 (SCHOR, 1996: 1039). O articulista utilizava o humor para reafirmar o local da mulher como aquela que deve servir e agradar o homem - sua voz será ouvida apenas quando ela estiver cantando - e ainda ridicularizava as demandas do incipiente movimento feminista como pouco importantes.

Mais de cemanos depois, o semanário OPasquim adotava, no Brasil, um discurso bastante semelhante, afirmando: "Olha aqui, a gente aqui d'O Pasquim é toda pelo feminismo, desde que seus representantes sejam do nível de Tânia Caldas ou Marina Montini” (SOIHET, 2005: 596). Eram os anos 1970, o Brasil vivia em plena ditadura militar e $O$ Pasquim se destacava na oposição ao regime. A publicação também estava inserida no contexto de contracultura e sua reação contra a moral tradicionalista. $\mathrm{O}$

8 No original: "I fear that buttons might be poorly sewn on pants from now on, worse yet, they might not be sewn back on at all after they have had the misfortune to fall. Buttons are a thing of the past! Down with buttons! Such will soon be the cry coming from all women's voices" (SCHOR, 1996: 1039). 
propósito libertário daqueles intelectuais ficava, porém, comprometido no momento em que voltavam à mesma mordacidade com que atacavam os militares em direção ao movimento feminista, como analisa Soihet (2005). Em trabalho sobre a "utilização dos discursos cômicos e/ou da palavra espirituosa como arma, a fim de manter a inferioridade feminina" (SOIHET, 2005: 593), a autora toma como objeto de análise justamente o período entre 1960 e 1980. É interessante notar as continuidades entre aquela época e um passado mais distante: a principal diferença no discurso de um jornal francês do século XIX e de uma publicação brasileira dita questionadora e inovadora nos anos 1970 é que o primeiro se referia à cantoras de ópera como modelo feminino, enquanto a segunda mencionava atrizes de televisão.

O feminismo, porém, já era objeto de escárnio no Brasil havia várias décadas. Como salientam Schumaher e Brazil (2000, p. 319), a luta de Leolinda Daltro, uma das pioneiras do movimento no Brasil, "se dera contra a mais cruel das armas dos adversários da mulher, o ridículo". Para se ter uma ideia do tipo de notoriedade negativa à qual ela era submetida, basta lembrar que, em 1917, sua figura esteve presente em três desfiles carnavalescos, com menções nada elogiosas. Segundo conta Karawejczyk (2013), chamavam-na de "barulhenta" e "mulher-homem" e pintavam-na como insensata e radical - críticas que a imprensa da época reputava como "espirituosas" e engraçadíssimas". Daltro também era comumente associada à sufragista inglesa Emmeline Pankhurst, justamente com o objetivo de enquadrar a brasileira como radical, uma vez que era esta a imagem que o movimento britânico detinha no Brasil. Karawejczyk (2013) lembra que o jornal "O Paiz" divulgava quase diariamente notícias sobre as sufragistas inglesas, dando ênfase aos incêndios, quebras de vidraças e ataques violentos, inclusive chegando a creditar a elas, sem provas, quaisquer atos de perturbação à ordem pública que ocorriam nos arredores de Londres.

A imagem destas militantes era tão negativa que, conforme o movimento foi crescendo no Brasil, as próprias mulheres que passaram a se aliar a ele sentiram necessidade de se desvincularem deste estereótipo nefasto. Bertha Lutz, que se tornou uma das principais lideranças da luta brasileira pelo voto feminino, se posicionava contra as sufragistas inglesas. Como recorda Hahner (1981: 101), Lutz afirmou que a liga fundada por ela não seria "uma associação de 'suffragettes' para quebrarem as vidraças da Avenida".

Bertha Lutz, portanto, procurou diferenciar-se do que se considerava um "mau feminismo" (KARAWEJCZYK, 2013: 244). Pinto (2003) opina que Lutz liderava um feminismo "bem-comportado", de modo a garantir trânsito entre a elite política. Ela não questionava, por exemplo, a organização das relações domésticas, tendo mesmo afirmado, em 1921: "O domínio da mulher, todas nós feministas concordamos, é o lar” (HAHNER, 1981:116). Esta fala, certamente, deve ser lida em seu contexto histórico - no qual o ideal da mulher como "anjo do lar" ainda não era contestado pela grande maioria das feministas - e também pode ser vista como um movimento estratégico. Mulher branca e intelectual, Lutz lançou mão de seus privilégios para tornar sua causa mais palatável. Esta atuação pode ter colaborado para o sucesso da 
causa sufragista no Brasil, entretanto, caracterizou-se por um elitismo que significou a exclusão de muitas mulheres das fileiras feministas. Além disso, não garantiu que as militantes pelos direitos das mulheres ficassem imunes às ironias e aos deboches - nem mesmo a própria Bertha Lutz.

Conforme demonstra análise de Moreira (2019), em 1928 - quando Lutz já atuava no movimento sufragista há anos - a revista "O Malho" ridicularizou-a como sendo infantil e emocional ao extremo. Mesmo em 1931, momento em que a causa já estava mais consolidada, a revista "Careta", ainda de acordo com Moreira (2019: 68), representa-a como uma reivindicação por "um pouco mais de dinheiro para o pó de arroz ou um lugar ao lado do marido nos cabarés". Vale lembrar que publicações como "O Malho" e "Careta" - baratas, bem impressas e de grande circulação nacional e internacional - detiveram papel de destaque como porta-vozes da condenação à militância feminista. Apesar de apresentarem tom humorístico, revistas como esta foram, tanto no Brasil como no exterior, instrumentos de ataque a oponentes políticos em vários momentos históricos. Deste modo, o posicionamento de descrédito à demanda do voto feminino não deve ser desconsiderado como pouco importante ou fruto de leviandade, mas sim precisa ser visto como um conteúdo estratégico, projetado e intencional.

Para melhor compreender o impacto desta visão sobre o feminismo marcada pela zombaria e pelo deboche, torna-se útil a categoria de soft repression, idealizada por Ferree (2004): a mobilização coletiva de poder para limitar ou excluir ideias e identidades do espaço público sem a necessidade do uso de força física ou coerção estatal. Apesar de o nome do conceito dar a entender que se trataria de uma forma de repressão amena e, portanto, pouco relevante para análise, em realidade ela pode funcionar de forma extremamente poderosa e efetiva para dificultar ou até mesmo bloquear a ação de movimentos sociais. É importante, entretanto, ressaltar a sua diferença em relação às ferramentas mais tradicionais de coibição, uma vez que, por não lançar mão das formas mais comuns e visíveis de violência, pode passar despercebida - ao ponto de inspirar o riso até mesmo entre cidadãos que se afirmam libertários.

Uma primeira forma de realizar esse outro tipo de repressão seria justamente através da ridicularização. Segundo a autora, essa tática está presente desde os anos escolares, quando os apelidos dados a certas crianças funcionam como policiamento das fronteiras de gênero e comportamento adequadas, até o momento em que se deseja diminuir e desarmar aqueles que se mobilizam para desafiar as estruturas sociais e culturais. E, ainda de acordo com Ferree (2004), essa é uma tática adotada em relação aos feminismos com muita frequência não porque sejam naturalmente mais engraçados e propícios às piadas, mas sim porque as questões relacionadas ao gênero demandam grandes mudanças culturais e de mentalidade, e a resposta para estas demandas se dá, também, neste nível. A grande vantagem deste método é que trata-se de uma forma de combater ideias sem deixar marcas - sem nem parecer que se está fazendo algum esforço para tal. 
Quando, a partir de repetidos atos de ridicularização, um grupo consegue enfraquecer a identidade coletiva de outro, tornando a associação com este movimento, por si só, fonte de descrédito, adentramos o que Ferree (2004) indica como o segundo

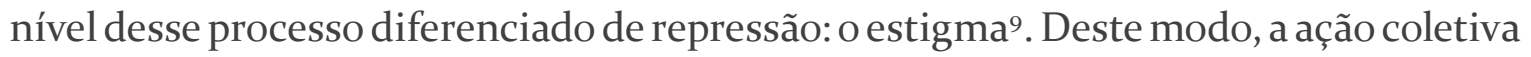
é prejudicada na medida em que a repressão dificulta a identificação dos indivíduos com o grupo que pretende representá-los contra determinadas instituições.

É o caso dos feminismos, cuja imagem - negativa desde o princípio de sua organização, como tenho demonstrado - faz com que muitas mulheres não se sintam confortáveis em se ver como parte do grupo e até mesmo declarem abjeção por ele, ainda que concordem com muitas de suas propostas. Williams e Witting (1997) destacam que, além da anuência ou não com seus princípios, um critério determinante para se apresentar como feminista ou antifeminista é o modo como feministas são enxergadas. Se houvesse uma visão positiva ou mesmo neutra na sociedade acerca destas militantes, talvez não houvesse a necessidade de mulheres conservadoras se afirmarem como contrárias ao feminismo.

O problema da falta de identificação de mulheres com o feminismo se agrava na medida que, como lembra Steuter (1992), quando um movimento social enfrenta a resistência de um contramovimento durante um longo período de tempo, tendea surgir um padrão de interdependência entre eles, até o ponto em que "o contramovimento eventualmente promova tudo o que os primeiros aderentes do movimento inicial buscavam"10 (STEUTER, 1992: 301). Isso é, no caso do daqueles que se colocam contra os feminismos, opor-se àquelas que consideram rivais se torna mais importante do que outras suas pautas originais. Ao mesmo tempo, o antifeminismo adota como seus os elementos que pertenciam à ideologia supostamente contrária.

O efeito desta estratégia é que este contramovimento consegue o poder de definir o que é feminismo, e o faz em duas partes: primeiro, aponta como pautas típicas de suas ditas antagonistas apenas as propostas mais radicais; em seguida, define a si mesmo como a alternativa oposta, enquanto toma das feministas diversas de suas ideias e práticas iniciais. Ocorre, em consequência disso, uma cisão, no imaginário coletivo, entre os feminismos e seus objetivos que cria uma imagem negativa do movimento e a preenche com todo tipo de estereótipos e acusações, enquanto, ao mesmo tempo, se aprovam as mudanças que foram trazidas pela ação política conjunta destas mulheres (FERREE, 2004).

9 Como lembra Goffman (1963), o termo estigma se originou a partir dos gregos, que o utilizavam para se referir a sinais dolorosamente impressos aos corpos de certos indivíduos, destinados a exibir a todos a condição de escravo, criminoso ou traidor. O estigma, até os dias de hoje, reduz o outro de uma pessoa comum e completa e alguém impuro, contaminado, inadequado. Ainda segundo o autor, em torno dessa diferença indesejada do outro, se constitui uma ideologia para explicar sua suposta inferioridade e imputar a esse indivíduo uma série de imperfeições que expandem o estereótipo inicial e pretendem justificar as atitudes tomadas contra ele.

10 No original: "Where movement and countermovement are of long standing, it is not infrequent for the countermovement eventually to promote everything the early adherents of the initial movement sought" (STEUTER, 1992: 301). 
Assim, apesar de ter conquistado diversas vitórias, como o direito ao voto e à propriedade, o divórcio e as leis contra violência doméstica, o trabalho de tantas mulheres em prol destas conquistas - inclusive enfrentando resistências conservadoras - não é reconhecido, e os feminismos são associados a um movimento de libertinagem e extremismos. Outro exemplo é a questão das donas de casa e mães: elas participaram dos feminismos a contar de seu início; mas, também desde esse momento, o movimento sofreu ataques a sua reputação que o pintaram como inimigo do lar. Em trabalho anterior sobre a retórica de páginas antifeministas no Facebook, foi possível perceber que, ainda hoje, no contexto brasileiro, feministas continuam a ser vistas por muitos como antagonistas de donas de casa e ameaçadoras à família e aos "bons costumes", enquanto as antifeministas conseguem se colocar como as únicas que se preocupam com a família e, portanto, as verdadeiras representantes dos interesses femininos (ANJOS, 2019).

Este tipo de movimento de estigmatização e deslegitimação do feminismo pode ser visto como parte do trabalho do ódio utilizado como ferramenta política. Afinal, como lembra, Aurel Kolnai (1998), o ódio possui um "movimento típico" em direção à destruição de seu objeto, mas este extermínio não precisa ser físico: humilhações e insultos, por exemplo, são eficientes maneiras de eliminação simbólica do outro.

Sobre a emoção de ódio, é importante lembrar, ainda, que o desejo por eliminação do ser odiado não significa necessariamente o fim (ou o caminho para o fim) da relação com este considerado inimigo. Ocorre, na verdade, o contrário: curiosamente, o desejo por expurgar o outro coloca o ser que odeia em constante relação com este outro. A experiência de inimizade característica do ódio se torna importante para a história do indivíduo e passa a representá-lo. Trazendo esta lógica para o campo político, podemos dizer que opor-se ao feminismo se torna relevante para definir o que é ser tradicionalista ou conservador. Esta imagem negativa do movimento pelas mulheres tende, portanto, a se perpetuar, ainda que tanto o feminismo quanto o conservadorismo mudem ao longo do tempo. Isso ocorre porque o ódio se caracteriza como uma emoção "teimosa", isto é, que perdura ao longo do tempo e é "extraordinariamente resistente à transformação" (BRUDHOLM, 2010: 309).

O fato de que o ser odiado se torna importante para definir o próprio grupo que odeia colabora para compreender por que nem sempre ocorre uma cruzada pela destruição completa daquele considerado como ameaça. Quando se discute antifeminismo, muitos podem questionar se realmente estamos falando de ódio, uma vez que jamais houve um projeto para eliminar feministas, como ocorreu e ainda ocorre com outros tipos de grupos políticos, religiosos e étnicos. Neste sentido, é importante lembrar que a destruição do sujeito odiado nem sempre consiste no objetivo final do ódio, como explica Kolnai (1998). O autor argumenta que mesmo a morte pode não ser suficiente para quem odeia, e "o ódio pode perdurar mesmo após a morte do inimigo e persegui-lo para além do túmulo. O odiador também pode 
tentar macular ou apagar a memória de seu inimigo; ele pode desejar condenação eterna de sua alma” (KOLNAI, 2013: 143, tradução livre) ${ }^{11}$.

Seria, deste modo, uma característica típica do ódio ter objetivos indefinidos e priorizar uma destruição simbólica de seu objeto. É interessante lembrar que um extermínio físico que não é acompanhada pela aniquilação da imagem do grupo odiado não é tão efetiva do ponto de vista político, uma vez que favorece a criação de mártires. Já a diminuição do poder emblemático de um objeto prescinde da eliminação corpórea, quando o fim é calar ou deslegitimar este outro.

\section{Observações finais}

Este artigo teve como objetivo a análise dos usos políticos da misoginia, tomando como recorte temporal a disputa pelo sufrágio feminino, ocorrida a partir do final do século XIX, nos Estados Unidos, na França e no Brasil. Mais especificamente, examinei três tipos de argumentações utilizadas para a repressão do movimento feminista, em sua fase embrionária, e discuti como elas mobilizavam a emoção de ódio.

Em primeiro lugar, demonstrei como o movimento antissufrágio utilizou amplamente a retórica de separação entre "mulheres honradas", moralmente superiores - aquelas que não se interessavam pelo voto e permaneciam no lar -, e "mulheres condenáveis" - aquelas que desejavam meter-se em assuntos políticos e eram caracterizadas, também, como desonestas e depravadas. Este estratagema demonstra que esta ação política apresentou uma especificidade: enquanto outros tipos de discurso de ódio geralmente agem por meio de uma generalização e homogeneização do grupo que pretendem atingir, a ação misógina também atua por meio de uma divisão do grupo-alvo. Assim, as mulheres "más" são caçadas e punidas, enquanto as mulheres "boas" servem de padrão de comportamento e auxiliam na punição das demais. É importante ressaltar, porém, que apesar desta separação, ao final todas as mulheres acabam sendo afetadas por este tipo de ódio: mesmo uma mulher considerada "boa" corre permanente risco de ser percebida como "má", uma vez que não é ela quem decide à qual categoria pertencer.

Em seguida, observei como foi construída a ideia de que as sufragistas eram uma grande ameaça à sociedade. Este tipo de argumentação é típico do modo como funciona o ódio: criando narrativas sobre o ser odiado, que costumam caracterizálo como uma ameaça perigosamente próxima, cuja mera presença é suficiente para colocar em risco um bem precioso ou mesmo tomar o lugar do sujeito ameaçado, impotente em meio a toda esta ação. Esta narrativa é uma tática política extremamente eficaz pois, além de fornecer uma sensação de importância e urgência ao discurso,

11 No original: No original: "hatred can outlast the enemy's death, and pursue him beyond the grave. The hater can also try to blacken or blot out his enemy's memory; he can wish eternal damnation on his soul". 
ainda permite que o ódio mobilizado seja ressignificado como sentimento de justiça, amor e proteção a valores importantes.

Por fim, discorri sobre como esta imagem negativa sobre o nascente feminismo se prolongou ao longo do tempo, ao ponto de ser possível falar em uma aniquilação simbólica, um estigma que prejudica a ação política deste grupo. Muitos podem questionar se realmente estamos falando de ódio quando se discute a repressão aos feminismos, uma vez que jamais houve um projeto de genocídio deste grupo, como ocorreu e ainda ocorre com outros tipos de coletivos políticos, religiosos e étnicos. Houve, entretanto, um processo de repressão que, sem utilizar violência física e, portanto, sem chamar a atenção, foi extremamente eficiente para formatar uma imagem coletiva negativa, que dificulta a identificação de muitas pessoas com o feminismo, em suas variadas correntes.

A ação da violência misógina sobre corpos femininos e feminizados é uma triste realidade, que marca de maneiras terríveis ou mesmo finda a vida de incontáveis mulheres ao redor do planeta. É preciso lembrar, porém, que o ódio tem na destruição simbólica outra poderosa ferramenta para levar a cabo projetos de eliminação de grupos considerados, por qualquer motivo, ameaçadores. Mesmo sem derramar uma gota de sangue, o ódio cumpre, com assustadora e prolongada eficácia, seu papel político de aniquilar visões diferentes da norma.

\section{Referências}

AHMED, Sara (2014). The cultural politics of emotion. Edinburgh: Edinburgh University Press.

ANJOS, Júlia dos (2019). Megeras (in)domadas: discurso de ódio antifeminista nas redes sociais. Dissertação (Mestrado em Comunicação e Cultura) - Programa de PósGraduação em Comunicação e Cultura, Escola de Comunicação, Universidade Federal do Rio de Janeiro, Rio de Janeiro.

BRUDHOLM, Thomas (2010). Hatred as an attitude. Philosophical Papers, v. 39, n. 3: p. 289-313.

FERREE, Myra Marx (2004). Soft repression: ridicule, stigma and silencing in gender based movements. In: MYERS, Daniel J.; CRESS, Daniel M. (Orgs.). Authority in contention: research in social movements, conflicts and change, v. 25. Bingley: Emerald Group Publishing Limited. p. 85 - 101.

FREEDMAN, Estelle (2002). No turning back: the history offeminism and the future of women. New York: Ballantine books. 
FRENIER, Miriam (1984). American anti-feminist women: comparting the rhetoric of opponents of the Equal Rights Amendment with that of opponents of women's suffrage. Women's Studies International Forum, v. 7, n. 6: p. 455-465.

GAY, Peter (1995). O cultivo do ódio. São Paulo: Companhia das Letras.

GOFFMAN, Erving (1963). Stigma. London: Penguin.

HAHNER, June E. A Mulher Brasileira e suas Lutas Sociais e Políticas. 1850-1937. São Paulo: Brasiliense, 1981.

HIGGINS, Lisa (2004). Adulterous individualism, socialism, and free love in nineteenth-century anti-suffrage. Legacy, v. 21, n. 2: p. 193-209.

KARAWEJCZYK, Mônica. As filhas de Eva querem votar: dos primórdios da questão à conquista do sufrágio feminino no Brasil (c.1850-1932). 2013. 398 f. Tese (Doutorado) Instituto de Filosofia e Ciências Humanas, Programa de Pós-Graduação em História, Universidade Federal do Rio Grande do Sul, Porto Alegre, 2013.

KING, Mae. The politics of sexual stereotypes. Black Scholar, n. 4, p. 12-23, 1973.

KOLNAI, Aurel (1998). The standard modes of aversion: fear, disgust and hatred. Mind, v. 107, n. 427: p. 581-596.

KOLNAI, Aurel (2013). An Essay on hatred (1935). In: MCALLER, Graham (Org.). Politics, Values, and National Socialism. London: Transaction publishers. p. 139-174.

KONSTAN, David (2018). Hate and state in Ancient Greece. In: BRUDHOLM, Thomas; JOHANSEN, Birgitte Schepelern (Orgs.). Hate, politics, law: critical perspectives on combating hate. Oxford: Oxford University Press. p. 34-49.

LORDE, Audre (1984). Age, Race, Class and Sex: Women Redefining Difference. In: LORDE, Audre. Sister outsider: essays and speeches. Berkeley: Crossing Press. p. 7680.

MANNE, Kate (2018). Down girl: the logic of misoginy. Nova Iorque: Oxford University Press.

MOREIRA, Thaís Batista Rosa. Os essencialismos de gênero pelo viés da ironia: o antifeminismo em publicações das revistas ilustradas humorísticas O Malho e Careta. Epígrafe, São Paulo, v. 7, n. 7, pp. 55-81, 2019. 
OFFEN, Karen. On the French origin of the words feminism and feminist. Feminist Issues, v. 8, n. 2, jun. 1988. p. 45-51.

PALCZEWSKI, Catherine H. (2005). The male Madonna and the feminine Uncle Sam: visual argument, icons, and ideographs in 1909 anti-woman suffrage postcards. Quarterly Journal of Speech, v. 91, n.4: p. 365-394.

PINTO, Céli Regina Jardim. Uma história do feminismo no Brasil. São Paulo: Fundação Perseu Abramo, 2003.

RENDALL, Jane. The origins of modern feminism: women in Britain, France and the United States 1780-186o. London: The Macmillan Press LTD, 1985.

RICHARDSON-SELF, Louise (2018). Woman-hating: on misogyny, sexism and hate speech. Hypatia, v. 33, n. 2: p. 1-17.

SCHOR, Laura Strumingher (1996). Politics and political satire: the struggle for the right to vote in Paris, 1848-1849. The European Legacy: Toward New Paradigms, v. 1, n. 3: p. 1037-1044.

SCHUMAHER, Shuma, BRAZIL, Érico Vital (Org.). Dicionário Mulheres do Brasil: de 1500 até a atualidade. Rio de Janeiro: Jorge Zahar, 2000.

SOIHET, Rachel (2005). Zombaria como arma antifeminista: instrumento conservador entre libertários. Estudos Feministas, v.13, n. 3: p. 591-612.

STERNBERG, Robert J.; STERNBERG, Karin (2008). The nature of hate. New York: Cambridge University Press.

STEUTER, Erin (1992). Women against feminism: an examination of feminist social movements and anti-feminist countermovements. Canadian Review of Sociology, v. 29, n. 3: p. 288-306.

WILLIAMS, Rachel; WITTING, Michele. "I'm Not a Feminist, But...”: Factors Contributing to the Discrepancy Between Pro-Feminist Orientation and Feminist Social Identity. Sex Roles, v. 37, 1997.

Recebido em 03/06/2020.

Aceito em 20/11/2020. 